\title{
Utility of Serum Procalcitonin in Diagnosing Paroxysmal Sympathetic Hyperactivity in Patients with Traumatic Brain Injury
}

\author{
Ashish Bindra ${ }^{1} \odot$, Vineet Chowdhary ${ }^{2} \odot$, Surya K Dube $^{3} \odot$ Keshav Goyal $^{4} \odot$, Purva Mathur $^{5} \odot$
}

\begin{abstract}
Background: Paroxysmal sympathetic hyperactivity (PSH) is a grave entity affecting patients following traumatic brain injury (TBI). It presents with cyclic and simultaneous fever, posturing, and other symptoms of sympathetic hyperactivity. Lack of diagnostic tests or biochemical markers and its propensity to mimic other common causes of fever in the neurotrauma intensive care unit (ICU) result in clinical dilemmas and management delay.

Case descriptions: We present a case series of four patients (two adults and two pediatrics) with TBI who developed PSH during ICU stay. These patients presented with fever along with variable symptoms of sympathetic hyperactivity. However, the value of serum procalcitonin (PCT) was not elevated, and management of PSH was started. Serial monitoring of PCT helped in differentiating fever due to PSH from sepsis and thus the institution of appropriate and timely treatment of PSH and also helped to use antibiotics rationally.

Conclusion: The use of serum PCT in differentiating sepsis from systemic inflammatory reaction and its role in the initiation and titration of antibiotics are well described. PSH is a common entity after TBI, causing episodic fever and sympathetic hyperactivity, often confused with infectious pathology. Our report proposes the role of serum PCT in differentiating PSH from infectious etiology and management of two different clinical entities.
\end{abstract}

Keywords: Paroxysmal sympathetic hyperactivity, PCT, Sepsis, Traumatic brain injury (TBI).

Indian Journal of Critical Care Medicine (2021): 10.5005/jp-journals-10071-23811

\section{INTRODUCTION}

Paroxysmal sympathetic hyperactivity (PSH) is a syndrome of simultaneous, paroxysmal transient sympathetic [increased heart rate, blood pressure (BP), respiratory rate, temperature, sweating, and motor (posturing)] activity generally in response to non-noxious stimuli in a subgroup of survivors of severe acquired brain injury. The time of onset of symptoms is variable, ranging from the first few hours of injury to months. It adds to morbidity and mortality in neurocritical patients. PSH often leads to unnecessary workup, medication use, prolonged hospital stays, and poor outcome.

A recently proposed clinical scoring system known as PSH assessment measure consisting of clinical feature scale score and diagnosis likelihood tool describes the clinical criteria to diagnose PSH. ${ }^{1}$ This categorizes PSH as unlikely, possible, and probable. However, the lack of any clear diagnostic test or biochemical markers hampers its definite diagnosis, and PSH remains a diagnosis of exclusion. Early fever in ICU following traumatic brain injury (TBI) is a predictor of PSH. Nevertheless, the incidence of fever is high in the neurotrauma intensive care unit (ICU). ${ }^{2}$ Paroxysms of high-grade fever with diaphoresis and with or without motor posturing has shown significant association with PSH, but at the same time patients with a history of penetrating or blunt trauma in ICU, on the ventilator, and with multiple invasive devices are quite likely to have a fever of infectious origin that may also be accompanied by similar autonomic symptoms of varying intensity. Sedation in ICU might mask the sympathetic overactivity associated with PSH. The administration of empirical antibiotics in trauma patients decreases the likelihood of isolating an organism from
1,3,4 Department of Neuroanesthesiology and Critical Care, All India Institute of Medical Sciences, New Delhi, India

${ }^{2}$ Department of Neurocritical Care, All India Institute of Medical Sciences, New Delhi, India

${ }^{5}$ Department of Lab Medicine, Jai Prakash Narayan Apex Trauma Center, All India Institute of Medical Sciences, New Delhi, India

Corresponding Author: Ashish Bindra, Department of Neuroanesthesiology and Critical Care, All India Institute of Medical Sciences, New Delhi, India, Phone: +91 8826417127, e-mail: dr_ashi2208@yahoo.com

How to cite this article: Bindra A, Chowdhary V, Dube SK, Goyal K, Mathur P. Utility of Serum Procalcitonin in Diagnosing Paroxysmal Sympathetic Hyperactivity in Patients with Traumatic Brain Injury. Indian J Crit Care Med 2021;25(5):580-583.

Source of support: Nil

Conflict of interest: None

culture. Distinguishing PSH from infection often becomes a clinical challenge.

Procalcitonin (PCT) has been found to differentiate sepsis from systemic inflammatory response syndrome with a pooled sensitivity and specificity of 0.77 and 0.79 , respectively. Initiation and continuation of antibiotics based on initial РCT levels have been proposed. ${ }^{3}$ We utilized PCT for differentiating infective fever and fever due to PSH since both entities have an overlapping presentation but different management approaches. We present a series of four patients with TBI wherein serial PCT testing helped

(0) Jaypee Brothers Medical Publishers. 2021 Open Access This article is distributed under the terms of the Creative Commons Attribution 4.0 International License (https://creativecommons.org/licenses/by-nc/4.0/), which permits unrestricted use, distribution, and non-commercial reproduction in any medium, provided you give appropriate credit to the original author(s) and the source, provide a link to the Creative Commons license, and indicate if changes were made. The Creative Commons Public Domain Dedication waiver (http://creativecommons.org/publicdomain/zero/1.0/) applies to the data made available in this article, unless otherwise stated. 
in early diagnosis of PSH and institution of appropriate treatment. Consent was obtained from the patient's family for publication.

\section{Case Descriptions}

We describe a series of four patients, two adults and two pediatric, admitted to neurotrauma ICU after TBI and developed a fever during the first week (ranging from 2 nd to 7 th day) (Table 1). All patients were intubated and were mechanically ventilated and sedated with intravenous fentanyl and midazolam. The fever episodes were accompanied by variable symptoms of sympathetic hyperactivity like tachycardia, tachypnea, rise in systolic BP, posturing, and diaphoresis as described in Table 1. Case 2 had episodes of desaturation up to $85 \%$ on pulse oximeter during posturing episodes.

The demographic and clinical features of the patients are summarized in Table 1. Since all patients suffered TBI and nosocomial infections, a common cause of fever at 48 hours could not be ruled out. However, episodic features of fever and sympathetic activity also pointed toward PSH. The urge of escalating antibiotics is usually immense during such situations. Serum PCT levels were sent at the time of appearance of fever in all the patients. The levels were not elevated, which ruled out the infectious cause and favored toward the diagnosis of PSH. So the patients were managed by prescribing treatment for PSH.

Patients with predominant tachycardia and spasticity were started on propranolol and baclofen. Case 2 required additional sedation with dexmedetomidine. However, Case 3 had predominant tachycardia and was managed only with propranolol.

This was followed by serial monitoring of PCT levels. During the second week, both adult patients (Cases 1 and 2) had elevated levels of serum PCT ( 28.7 and $71.8 \mathrm{ng} / \mathrm{mL}$, respectively) and were investigated further for the presence of infections. There was microbial growth in the blood culture of both the patients, and culture-specific antimicrobials were added along with drugs used for the management of PSH. Both the pediatric patients (Cases 3 and 4) showed no rise in serum $P C T$, and hence, no antibiotic escalation was done.

Table 1: Clinical course of the patients

\begin{tabular}{|c|c|c|c|c|}
\hline & Case 1 & Case 2 & Case 3 & Case 4 \\
\hline Age in years and sex & 25 and male & 2 and male & 32 and male & 8 and male \\
\hline Mechanism of injury & Road traffic accident & Fall from height & Road traffic accident & Road traffic accident \\
\hline Admission GCS & E1V1M5 & E1V1M5 & E2V3M5 & $\mathrm{E} 2 \mathrm{~V} 2 \mathrm{M} 4$ \\
\hline $\begin{array}{l}\text { Intubation and mechanical } \\
\text { ventilation }\end{array}$ & Yes & Yes & Yes & Yes \\
\hline Neurosurgical intervention & $\begin{array}{l}\text { Conservative } \\
\text { management }\end{array}$ & $\begin{array}{l}\text { Conservative } \\
\text { management }\end{array}$ & $\begin{array}{l}\text { Conservative } \\
\text { management }\end{array}$ & $\begin{array}{l}\text { Conservative } \\
\text { management }\end{array}$ \\
\hline $\mathrm{NCCT}^{*}$ head & $\begin{array}{l}\text { Multiple dot contusions } \\
\text { Left frontal bone fracture } \\
\text { with } \mathrm{IVH}^{* *}\end{array}$ & $\begin{array}{l}\text { Left temporal contusion } \\
\text { Lt and Rt parietal bone } \\
\text { fracture } \\
\text { Bilateral IVH }\end{array}$ & $\begin{array}{l}\text { Rt FTP fracture } \\
\text { Subdural hemorrhage } \\
\text { Midline shift and mass } \\
\text { effect }\end{array}$ & $\begin{array}{l}\text { Rt fronto-temporo-parietal } \\
\text { hemorrhagic contusions } \\
\text { IVH }\end{array}$ \\
\hline $\begin{array}{l}\text { First episode of fever and } \\
\text { symptoms: } \\
\text { Tachycardia } \\
\text { Tachypnea } \\
\text { SBP elevation } \\
\text { Posturing } \\
\text { Diaphoresis }\end{array}$ & $\begin{array}{l}\text { Day } 2\left(101^{\circ} \mathrm{F}\right) \\
\text { Yes } \\
\text { Yes } \\
\text { Yes } \\
\text { Yes } \\
\text { Yes }\end{array}$ & $\begin{array}{l}\text { Day } 7\left(103.6^{\circ} \mathrm{F}\right) \\
\text { Yes } \\
\text { Yes } \\
\text { Yes } \\
\text { Yes } \\
\text { Yes }\end{array}$ & $\begin{array}{l}\text { Day } 4\left(102^{\circ} \mathrm{F}\right) \\
\text { Yes } \\
\text { Yes } \\
\text { Yes } \\
\text { Yes } \\
\text { Yes }\end{array}$ & $\begin{array}{l}\text { Day } 5\left(102^{\circ} \mathrm{F}\right) \\
\text { Yes } \\
\text { Yes } \\
\text { Yes } \\
\text { Yes } \\
\text { Yes }\end{array}$ \\
\hline $\begin{array}{l}\text { Culture and PCT values (ng/ } \\
\mathrm{mL} \text { ) in the first week (on the } \\
\text { appearance of symptoms) }\end{array}$ & $\begin{array}{l}\text { No growth } \\
0.18\end{array}$ & $\begin{array}{l}\text { No growth } \\
0.30\end{array}$ & $\begin{array}{l}\text { No growth } \\
0.28\end{array}$ & $\begin{array}{l}\text { No growth } \\
0.11\end{array}$ \\
\hline Clinical feature scale & 11 & 13 & 16 & 9 \\
\hline Diagnosis likelihood tool & 10 & 10 & 10 & 9 \\
\hline Total score/PSH & 21. Probable & 23. Probable & 26. Probable & 18. Probable \\
\hline Management drugs & $\begin{array}{l}\text { Propranolol } 20 \text { mg BD } \\
\text { Baclofen } 10 \mathrm{mg} \mathrm{BD}\end{array}$ & $\begin{array}{l}\text { Propranolol } 5 \mathrm{mg} \mathrm{BD} \\
\text { Baclofen } 5 \mathrm{mg} \mathrm{BD} \\
\text { Dexmetomidine } 0.7 \mathrm{\mu g} / \\
\mathrm{kg} / \mathrm{hr} \text { for } 24 \mathrm{hrs}\end{array}$ & Propranolol 20 mg BD & $\begin{array}{l}\text { Propranolol } 5 \text { mg BD } \\
\text { Baclofen } 5 \text { mg BD }\end{array}$ \\
\hline $\begin{array}{l}\text { Subsequent clinical course } \\
\text { Culture and PCT values (ng/ } \\
\mathrm{mL} \text { ) }\end{array}$ & $\begin{array}{l}\text { Day 9: PCT } 28.7 \mathrm{ng} / \mathrm{mL} \\
\text { Day 12: Klebsiella growth } \\
\text { in blood culture }\end{array}$ & $\begin{array}{l}\text { Day 15: РСТ } 71.8 \mathrm{ng} / \mathrm{mL} \\
\text { Day 17: Klebsiella growth } \\
\text { in blood culture }\end{array}$ & $\begin{array}{l}\text { Week } 2 \\
\text { PCT } 0.82 \mathrm{ng} / \mathrm{mL} \\
\text { No cultures found } \\
\text { positive }\end{array}$ & $\begin{array}{l}\text { Week } 2 \\
\text { PCT } 0.56 \mathrm{ng} / \mathrm{mL} \\
\text { No cultures found positive }\end{array}$ \\
\hline Revised management & $\begin{array}{l}\text { Culture-sensitive antibi- } \\
\text { otics added }\end{array}$ & $\begin{array}{l}\text { Culture-sensitive antibi- } \\
\text { otics added }\end{array}$ & - & - \\
\hline Outcome & $\begin{array}{l}\text { Symptoms gradually } \\
\text { improved. }\end{array}$ & $\begin{array}{l}\text { Death due to septic } \\
\text { shock. }\end{array}$ & $\begin{array}{l}\text { Symptoms gradually } \\
\text { improved. }\end{array}$ & $\begin{array}{l}\text { Symptoms gradually } \\
\text { improved. }\end{array}$ \\
\hline
\end{tabular}


Along with clinical features, measuring PCT levels helped us in early differential diagnosis and appropriate management without unnecessary antibiotic escalation.

\section{Discussion}

PSH has a reported incidence of $7.7-33 \%$ and is predominantly observed after TBI (80\%). ${ }^{1,2}$ Other causes include hypoxic brain injury (9.7\%), stroke (5.4\%), post-cardiac arrest, and subarachnoid hemorrhage (SAH). PSH episodes are characterized by hyperthermia, hypertension, tachycardia, tachypnea, posturing, and diaphoresis. There are different stages of PSH manifestations; the first stage has a variable combination of symptoms that can remain masked due to sedation; the second stage is characterized by clusters of symptoms with the withdrawal of sedation, and the third stage witnesses a decline in dystonia and posturing, but residual muscle spasticity adds to morbidity and delayed rehabilitation. ${ }^{4}$

PSH symptoms in the first stage may not be overt in ICU in an acutely injured patient receiving sedatives and paralytics. However, early fever as a predictor of PSH in TBI should always be remembered. ${ }^{2}$ Fever in ICU during the first week can be easily attributed to injury and infection due to multiple invasive lines and mechanical ventilation. Identifying the cause of fever is important for appropriate management.

Due to the similarity in symptoms and lack of any definite diagnostic test, diagnosis of PSH requires a high index of suspicion. This often leads to delay in diagnosis, misdiagnosis, inappropriate therapy, unwarranted side effects, and increased morbidity. Fever in neurologically injured can be attributed to include PSH, central fever, seizure, and sepsis along with other causes like neuroleptic malignant syndrome, malignant hyperthermia, and pulmonary embolism. In contrast to PSH which is mostly seen in TBI, central fever is seen in patients with $\mathrm{SAH}$, intracranial hematoma, or ischemia. It is a continuous fever with no triggering factors and occurs within 24 to 72 hours of the injury, presence of relative bradycardia, and absence of motor posturing. ${ }^{3}$ In our patients with lack of overt seizures, electrocardiographic abnormalities, no exposure to dopamine blockers, or inhalational anesthetics, normal thyroid profile ruled out other causes of fever.

Measurement of PCT along with clinical symptom levels helped us in timely differentiation between the two. All of our four patients had PSH symptoms within the first week of admission, and all had a fever as one of the manifestations (Table 1). PCT sent during the early phase of onset of fever was less than $1 \mathrm{ng} / \mathrm{mL}$, and such low levels of PCT in the first few days after major trauma indicate noninfectious systemic response. Later, negative cultures reinforced the same. In our case, PCT assay helped in excluding infection as a cause of fever, leading to avoidance of unnecessary antibiotic administration during the first week. Subsequent PCT values showed an increasing trend in two out of the four patients indicating infective etiology, and appropriate antibiotics were instituted following the sensitivity report. We lost one patient to septic shock in whom PCT values jumped during the subsequent measurements.

Management of PSH includes identifying the triggers like change in position, urinary retention, or suctioning and avoiding them if possible and pharmacologic measures to abolish the symptoms. ${ }^{5}$ Drugs target the opioid, GABA, $\alpha-2$, D2 receptors in the brain and spinal cord, and $\alpha$ and $\beta$ adrenoceptors in the periphery and brain. Drugs frequently used in the management include opioids, $\alpha$ and $\beta$ blockers, central $\alpha-2$ receptor agonists, benzodiazepine, gabapentin, and baclofen. ${ }^{7}$ Other supportive measures include prevention of fever, physiotherapy, and positioning to prevent contractures and nutritional supplementation. ${ }^{6}$

PCT is a calcitonin precursor and is a marker of bacterial infection. Healthy individuals have levels $<0.05 \mathrm{ng} / \mathrm{mL}$. It is a stable marker of bacterial infection with multiple advantages over C-reactive protein. ${ }^{7}$ Blood cultures are the gold standard for the confirmation of bacteremia. However, blood cultures take time, and studies have shown that the decision to start or withhold antibiotics may be taken with PCT values alone or in combination with other markers like white blood cell count which are available rapidly. ${ }^{8}$ Apart from this, its utility has also been described in differentiating systemic inflammatory response from infection in patients with $\mathrm{SAH} .{ }^{9}$ Beyond this, the role of PSH in the neurocritical care arena needs to be explored.

This report proposes the utilization of PCT for supporting the diagnosis of PSH. These are preliminary findings that need to be replicated in large studies. We also believe that PSH may coexist along with sepsis, and results and clinical symptoms need to be carefully observed.

\section{Conclusion}

The use of serum PCT in differentiating sepsis from systemic inflammatory reaction and its role in the initiation and titration of antibiotics are well described. We wish to highlight the possible role of serum PCT as an ancillary marker to differentiate PSH from infectious etiology early in the course of the disease. The negative predictive value of a low or normal PCT level in PSH will help to rule out infection and stop antibiotic therapy and start appropriate timely management of PSH.

Research Quality and Ethics Statement: The authors of this manuscript declare that this scientific work complies with reporting quality, formatting, and reproducibility guidelines set forth by the EQUATOR Network. The authors also attest that this clinical investigation was not determined to require Institutional Review Board / Ethics Committee review. Finally, the authors have not registered this case report with Clinical Trial Registry.

\section{ORCID}

Ashish Bindra (1) https://orcid.org/0000-0001-5685-2833

Vineet Chowdhary $\odot$ https://orcid.org/0000-0003-2750-8667

Surya KDube 난 https:/orcid.org/0000-0002-0224-360X

Keshav Goyal (1) https://orcid.org/0000-0001-9139-0689

Purva Mathur $\odot$ https://orcid.org/0000-0003-4429-3688

\section{References}

1. Baguley IJ, Perkes IE, Fernández Ortega JF, Rabinstein AA, Dolce G, Hendricks HT, et al. Paroxysmal sympathetic hyperactivity after acquired brain injury: consensus on conceptual definition, nomenclature, and diagnostic criteria. J Neurotrauma 2014;31(17):1515-1520. DOI: 10.1089/neu.2013.3301.

2. Hinson HE, Schreiber MA, Laurie AL, Baguley IJ, Bourdette D, Ling GSF. Early fever as a predictor of paroxysmal sympathetic hyperactivity in TBI. J Head Trauma Rehabil 2017;32(5):E50-E54. DOI: 10.1097/ HTR.0000000000000271.

3. Sager R, Kutz A, Mueller B, Schuetz P. Procalcitonin-guided diagnosis and antibiotic stewardship revisited. BMC Med 2017;24:(1):15. DOI: 10.1186/s12916-017-0795-7. 
4. Hocker SE, Tian L, Li G, Steckelberg JM, Mandrekar JN, Rabinstein AA. Indicators of central fever in the neurologic ICU. JAMA Neurol 2013;70(12):1499-1504. DOI: 10.1001/jamaneurol.2013.4354.

5. Rabinstein AA, Benarroch EE. Treatment of paroxysmal sympathetic hyperactivity. Curr Treat Options Neurol 2008;10(2):151-157. DOI: 10.1007/s11940-008-0016-y.

6. Mehta NM, Bechard LJ, Leavitt K, Duggan C. Severe weight loss and hypermetabolic paroxysmal dysautonomia following hypoxic ischemic brain injury: the role of indirect calorimetry in the ICU. JPEN J Parenter Enteral Nutr 2008;32(3):281-284. DOI: $10.1177 / 0148607108316196$.
7. Massaro KS, Costa SF, Leone C, Chamone DA. PCT (PCT) and C-reactive protein (CRP) as severe systemic infection markers in febrile neutropenic adults. BMC Infect Dis 2007;7:137. DOI: 10.1186/1471-2334-7-137.

8. Takuya H, Hideki N, Hideki K, Shinobu I, Madoka N, Saori A, et al. Clinical value of PCT for patients with suspected bloodstream infection. Am J Clin Pathol 2014;141(1):43-51. DOI: 10.1309/ AJCP4GV7ZFDTANGC.

9. Festic E., Siegel J, Stritt M, Freeman WD. The utility of serum PCT in distinguishing systemic inflammatory response syndrome from infection after aneurysmal subarachnoid hemorrhage. Neurocrit Care 2014;20(3):375-381. DOI: 10.1007/s12028-014-9960-4. 